\title{
Investigating the effect of work life quality and social capital on the organizational commitment
}

\author{
Mahmood Reza Esmeili ${ }^{\mathrm{a}}$, Hojat Vahdati ${ }^{\mathrm{a}}$ and Milad Amraei ${ }^{\mathrm{b}^{*}}$
}

${ }^{a}$ Assistant Professor, Management Department, Lorestan University, Khoram Abad, Iran ${ }^{b}$ Master of Art in business management, Lorestan University, Iran

\section{H R O N I C L E}

Article history:

Received January 20, 2014

Accepted 5 July 2014

Available online

July 102014

Keywords:

Quality of work life

Social capital

Organizational commitment

Walton model

\section{Introduction}

The human resources are of the most fundamental strategic resources of every organization. The success of organizations and work places depends on the efficient use of human resources based on the behavioral sciences. In order to deal with the challenge of the efficient use of these resources, it is necessary to identify the concepts and structures associated with them and special tools within them (Hersey et al., 1996). The current organizations with a strategic attitude to human resources consider it as a valuable and intelligent asset (Hatami Hosseini \& Muhahidi Jahromi, 2011). The quality of work life is one the most important subjects of human resources management in organizations. This concept with its widespread trend in the two past decades has influenced many things such as management conditions, the quality of service compensation, etc. Dolan et al. (2008) examined the relationship between job demands, employees' motivation and resources, and supervisory support on employees' quality of work lives and their general health.

*Corresponding author. Tel: $+98-9169573228$

E-mail addresses: milad.amraei@yahoo.com (M. Amraei)

C 2014 Growing Science Ltd. All rights reserved. doi: $10.5267 / \mathrm{j} . \mathrm{ms} 1.2014 .7 .010$ 
Lau (2000) provided an ad hoc analysis of two key elements of the service profit chain. The study explored the direct linkage between performance in growth and profitability and quality of work life, which is a proxy for internal service quality in the service profit chain model. Hosseini et al. (2009) studied the relationship between the quality of work life and organizational commitment of physical training department in Esfahan province. Richards et al. (1994) determined prediction of the organizational commitment of marketing education and health occupations education teachers by work related rewards.

In the previous studies, the concept of quality has been investigated from different aspects but in most researches the Walton model (job environment features) or a mixture of this model has been consider. Therefore, in the present research, we use the eight-dimension model of the quality of work life of Walton as follows:

Fair pay: equal pay for equal work and the proportion of pays with social criteria of staff and other kinds of work,

Safe and sanitary workplace: providing with safe workplace physically and specifying rational work hours,

Supplying the growth opportunity and continuous security: providing improvement field for individual abilities, advanced opportunities, opportunities to apply acquired skills and social security in the field of employment and finance,

Legalism level in organization: supplying the pure freedom without any fear the superior interaction and legal dominate over the human dominate,

Social dependents work life: the way the staff makes impression about social responsibilities in organization,

Total space and life: creating balance between work life and the other life parts of staff including free time, education and family life,

Social cohesion in work organization: creating a suitable work atmosphere that fortifies the sense of relation of the staff to organization which is needed for the organization,

Developing the individual capabilities: providing opportunities such as the application of independence and self-control in work and benefiting from different skills and access to the information related to work (Walton, 1973; Taherian et al, 2011; Griffin \& Moorhead, 2011).

Social capital is another important valuable asset, which has a crucial place in this field. Social capital is a modern concept, which plays a crucial role in the organizations in communities more than physical and human capital. Today the concept of social capital has widely been used in sociology and economics and more recently in management and organization. The concept of social capital indicates the connections and communications among members of a channel as valuable resource and it will fulfill the objectives of the members by creating norms and reciprocal trust. In the absence of social capital, other capital will lose their efficacy and make the development trend and cultural economical evolvement rough and hard. Social capital whether in the macro-management level or in the management level of organizations and agencies can create a new knowledge of the socioeconomical systems and help the managers better control the organizational system (Seyed Naqavi \& Baharlou,2009). Obviously, there is not a general agreement about the dimensions of social capital. Every research has presented a different classification of social capital. The most well-known of whom are Nahapiet and Ghoshal (1998), which considered three dimensions for the social capital including cognitive, structural, and communicative dimensions (Krause et al., 2007). We have benefited from these dimensions in our research: 
1.The cognitive dimension of social capital: this dimension includes the staff participation level in social capital within a point of view or a common understanding among them; it also deals with the nature of interaction between the individuals in an organization like the communicative dimension (Bolino et al., 2002). Moreover, it contains the common codes, language along with the common interpretation (Nahapiet \& Ghoshal, 1998). In other words, this dimension is associated with the resources that provide for the groups a common interpretation. It also explains that the common definitions such as values and common goals are developed due to continuous participation in the meaningful process when the groups create a common understanding (Krause et al., 2007).

2. The structural dimensional social capital: this dimension is associated with the interaction among actors who continuously are sharing the information. Nahapiet and Ghoshal (1998) argued that having such information would lead to the capability promotion of organization to attract and combine knowledge so that it could create a competitive advantage for the organization. The structural dimension of the social capital includes the network relationship between individuals; making the network configuration and organization suitable (Nahapit \& Goshal, 1998).

3. The communicative dimension of the social capital: this dimension includes the nature of relationship in an organization. In other words, the communicative extension focuses on the nature and quality communication in the organization (Bolino et al., 2002).This dimension contains trust, norms, commitments and identity (Nahapit \& Goshal, 1998).

The organizational commitment is another important variable having a high stand in the organizational behavior. The organizational commitment is defined as a loyalty to the organization. The subject of organizational commitment has attracted the attention of most researchers in recent years because the researches show that the staff with commitment to the organization could have more productivity; their tendency to stay is more and they will be less absent and show more flexibility against the changes in organization. On the other hand, the organizational commitment is complicated phenomenon having various resources as well as being different in various societies (Fakhrparvar et al., 2012).

The national organizational commitment in recent decade is considered as one of the effective determinant of the organization due to the staff understanding from the commitment and generally regardless of this commitment is a popular research subject among the behavioral and organizational researches (Fiorito et al., 2007). Because of the numerous definition as well as avoiding repetition and according Allen and Meyer (1990), the organizational commitment has three dimensions as follows:

1. Affective commitment: it is recognized as the affective dependence of the individual to the organization and being identified through it. The employee will remain in the organization by a strong affective commitment because they wish to stay in the organization.

2. Continuous commitment: this theory is based on this fact that the individual aggregate the capital during time so that the more record the person has, the more aggregated capital he will have and losing this capital will be costly for him.

3. Normative commitment: the second factor of the organizational commitment is normative commitment which indicates a kind of duty sense to continue co-operation with organization. The people with a high-level of normative commitment feel that they have to remain in the present organization.

This study focuses on this subject and the result can play a crucial role in the improvement of the organizational commitment, social capital and staff performance. 
Table 1

A sample of the researches based on this research subject

\begin{tabular}{|c|c|}
\hline researcher & results \\
\hline Sayadi,Jamali \& Mansori (2009) & $\begin{array}{l}\text { There is a positive and meaningful relationship between quality of work life and organizational } \\
\text { commitment if the staff in educational office of Yazd. }\end{array}$ \\
\hline Talebpour \& Imami (2006) & $\begin{array}{l}\text { There is a meaningful co-relation between the organizational commitment and job attachment. Also there is } \\
\text { a meaningful relationship between the extents of the organizational commitments and quality of work life }\end{array}$ \\
\hline $\begin{array}{l}\text { Mehdad, Mahdavi rad \&Golparvar } \\
\text { (2011) }\end{array}$ & $\begin{array}{l}\text { There is meaningful relationship between the quality of work life, organizational commitment and its } \\
\text { components. Also the extents of quality of work life predict the organizational commitment and its } \\
\text { components. }\end{array}$ \\
\hline Hosseini et al (2009) & $\begin{array}{l}\text { There is a positive and meaningful co-relation between the quality of work life and organizational } \\
\text { commitment of physical education staff in Esfahan province. Also the regression analysis showed that the } \\
\text { affective commitment and normative commitment were influenced by the quality of the physical education } \\
\text { staff in Esfahan province. }\end{array}$ \\
\hline Taherian, kamran,Kafashi(2011) & $\begin{array}{l}\text { There is a meaningful relationship up to an above average level between the eight components of Walton's } \\
\text { quality of work life with the dependent variable social capital. }\end{array}$ \\
\hline Seyed naqavi \& Bahrlo (2009) & $\begin{array}{l}\text { The social capital generally has a meaningful relationship with the improvement of the organizational } \\
\text { commitment staff specially the improvement of affective commitment }\end{array}$ \\
\hline Khorshid (2012) & $\begin{array}{l}\text { The social capital has a direct effect on the organizational commitment of the staff along with the normative } \\
\text { and affective commitments in the level } \alpha=0.01 \text { while there was no meaningful effect on the continuous } \\
\text { commitment of the staff. }\end{array}$ \\
\hline Alexander et al, (2013) & $\begin{array}{l}\text { Organizational investment in the social capital affects the commitment of the service staff, job and } \\
\text { citizenship performance }\end{array}$ \\
\hline Macke,Genari,Faccin(2012) & $\begin{array}{l}\text { Normative and affective organizational commitments increase the development of social capital especially } \\
\text { in the cognitive and communicative fields. }\end{array}$ \\
\hline Kang (2012) & $\begin{array}{l}\text { social workers will merely understand those levels of social capital which are higher than average. } \\
\text { Realities and norms have a positive effect on the social staff satisfaction as well as organizational } \\
\text { commitment. }\end{array}$ \\
\hline Lee et al (2008) & $\begin{array}{l}\text { The staff attitudes towards organization depend on the services that the organization provides them so that } \\
\text { the desired quality of these services makes a positive face from the organization and finally increases the } \\
\text { organizational commitment of the staff. }\end{array}$ \\
\hline
\end{tabular}

Fig. 1 demonstrates the summary of the proposed study.

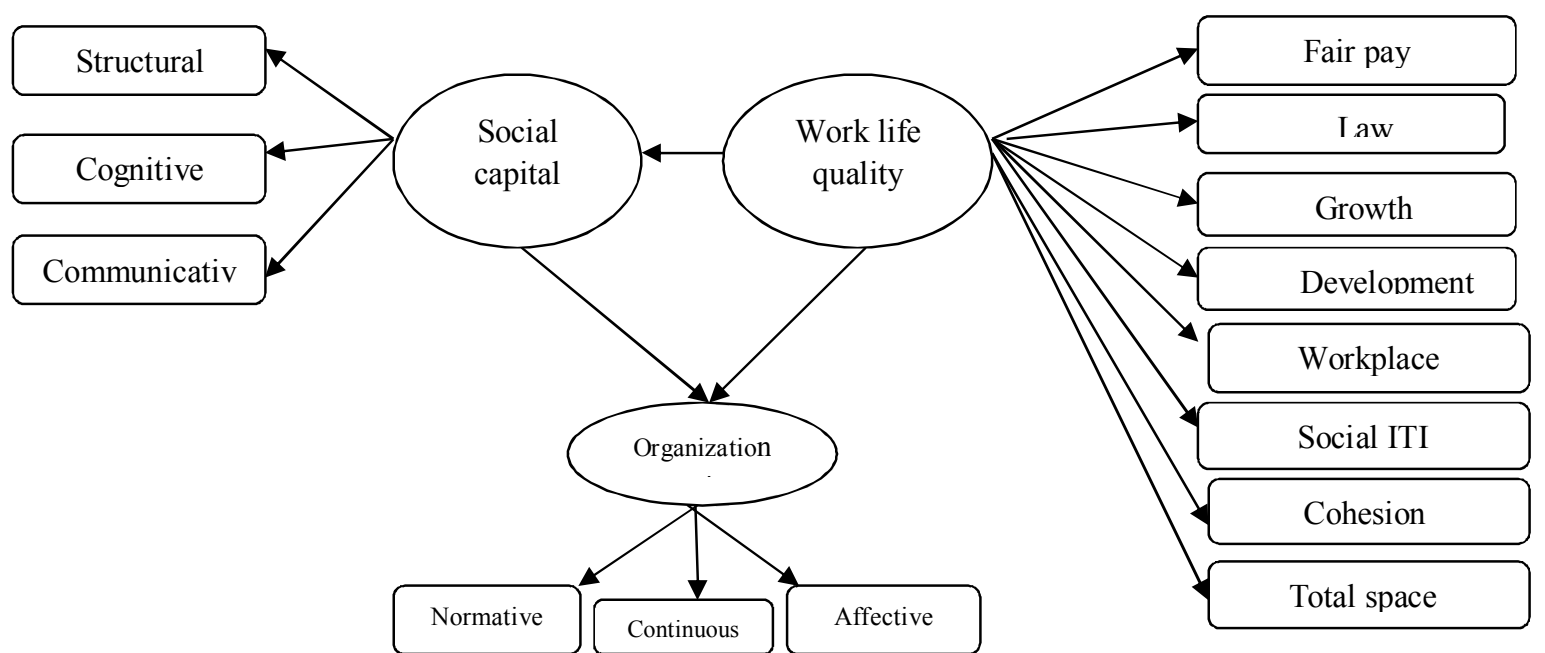

Fig. 1. The conceptual model of research

The research hypotheses:

Major hypotheses: 1. The quality level of staff's work life is effective on the organizational commitment. 2. The level of social capital is effective of the organizational commitment. 3 . The quality level of staff's work life is effective on the social capital of organization.

\section{Minor hypotheses:}

1. Work life quality is effective on the staff's affective commitment. 2. Work life quality is effective on the staff's continuous commitment. 3. Work life quality is effective on the staff's normative 
commitment. 4. Social capital is effective on the staff's affective commitment. 5. Social capital is effective on the staff's continuous commitment. 6. Social capital is effective on the staff's normative commitment. This research is an applied research in terms of purpose and by nature is a descriptive survey research, which studies the relationship between variables of the conceptual model. In terms of place, it has been conducted in the tax affairs organization staff. In this research due to the limitation of the statistical population within the staff of tax affairs offices in Lorestan province we have used a quantitative limited sample size estimation method as follows:

$n=\frac{N \cdot p \cdot q \cdot\left(Z \frac{\alpha}{2}\right)^{2}}{(N-1) \cdot d^{2}+p \cdot q \cdot\left(Z \frac{\alpha}{2}\right)^{2}}$

In this research $\mathrm{N}=900, \alpha=0.05, \mathrm{P}=0.5, \mathrm{q}=0.5, \mathrm{~d}=0.7$ has been considered. Therefore, the sampling case includes 204 staff of the tax affairs organization Lorestan province selected by a Stratified quota sampling method of different offices randomly. In this research, the data related to the theoretical principles were collected using library study and secondary resources such as internal and external articles as well as the necessary data to study the hypotheses and the conceptual model test through a field study with the aid of a questionnaire. The structural equation modeling method to study the relationship between the internal and external variables as well as the confirmatory factor analysis method to study the relationship between the model variable with the statistical measurement indices (the measurement model) with the help of LISREL software were applied so that it can specify the level and the effect of each factor on the organizational commitment. The questionnaire has made up of two sections:

Section one: it includes the features of the cognitive population of the participants such as gender, marital status, age and education. The second section includes 58 specialized questions, which has been used to measure work life quality from the standard questionnaire adapted from Walton's eightdimension model (1973) including 27 questions. This questionnaire evaluates the dimension of fair pay, law level in the organization, Supply rate of growth opportunities, development of individual capabilities, safe and sanity workplace, social dependence of work life, social cohesion in organization and total space of work life. To evaluate the social capital, we used the 14-question questionnaire of the Tsai \& Ghoshal (1998), Chiu et al. (2006), Fussell et al. (2006). The structural, cognitive and communicative dimensions of social capital have been located in this questionnaire, in order to evaluate the organizational commitment. We used the 17-question questionnaire adopted from Meyer and Allen (1991), Mathews and Shepherd (2002), Mowday et al. (1979), Powell (2004), which evaluates the affective, continuous, and normative dimension of the organizational commitment.

\section{Statistical observations}

\subsection{Test normality data}

The assumption of data normality has been tested with a 0.05 meaningful level with the KolmogorovSmirnov technique. Therefore there is no reason to reject the data normality. In other words, the research data is normal so we can perform the parametric tests.

\subsection{Confirmatory factor analysis}

In our study, the standard factor load of confirmatory factor analysis measuring the degree of relationship between every factor (hidden variable) with noticeable variables (questionnaire items) in all cases was obtained higher than 3\%. Therefore, the questionnaire factor structure of the work life quality, social capital, and organizational commitment has been confirmed. After calculating the standard factor load, there should be meaningful test. The load factor statistical of $t$ shows the evaluation indices of each dimension of the study case in the certainty level of $5 \%$ is an amount higher than 1.96. Therefore, the observed co-relations are meaningful. 
Table 2

The standard factor load, meaningful statistics (t-value) scale of work life quality

\begin{tabular}{|c|c|c|c|c|c|c|}
\hline Major variable & Minor variables & Factor load & $\mathrm{t}$-value & questions & Factor load & t-value \\
\hline \multirow{27}{*}{ Work life quality } & \multirow{3}{*}{ Fair pay } & \multirow{3}{*}{0.57} & \multirow{3}{*}{7.56} & 1 & 1 & 9.82 \\
\hline & & & & 2 & 0.32 & 9.65 \\
\hline & & & & 3 & 0.31 & 9.64 \\
\hline & \multirow{3}{*}{ Safe and sanity work place } & \multirow{3}{*}{0.39} & \multirow{3}{*}{11.11} & 3 & 0.39 & 8.95 \\
\hline & & & & 5 & 0.64 & 7.1 \\
\hline & & & & 5 & 0.32 & 3.8 \\
\hline & \multirow{3}{*}{$\begin{array}{l}\text { Supply rate of growth } \\
\text { opportunity }\end{array}$} & \multirow[t]{3}{*}{0.48} & \multirow{3}{*}{8.3} & 7 & 0.46 & 7.96 \\
\hline & & & & 8 & 0.79 & 12.61 \\
\hline & & & & 9 & 0.79 & 12.57 \\
\hline & \multirow{4}{*}{ law level in organization } & \multirow{4}{*}{0.48} & \multirow{4}{*}{11.19} & 10 & 0.69 & 11.77 \\
\hline & & & & 11 & 0.60 & 9.83 \\
\hline & & & & 12 & 0.56 & 10.58 \\
\hline & & & & 13 & 0.43 & 7.3 \\
\hline & \multirow{3}{*}{ Social dependence of work life } & \multirow{3}{*}{0.50} & \multirow{3}{*}{12.59} & 14 & 0.48 & 7.94 \\
\hline & & & & 15 & 0.45 & 6.62 \\
\hline & & & & 16 & 0.73 & 10.24 \\
\hline & \multirow{3}{*}{ Total space of work life } & \multirow{3}{*}{0.59} & \multirow{3}{*}{13.33} & 17 & 0.75 & 11.08 \\
\hline & & & & 18 & 0.56 & 9.36 \\
\hline & & & & 19 & 0.71 & 10.98 \\
\hline & \multirow{4}{*}{$\begin{array}{l}\text { Social cohesion in } \\
\text { organization }\end{array}$} & \multirow{4}{*}{0.56} & \multirow{4}{*}{15.76} & 20 & 0.93 & 8.14 \\
\hline & & & & 21 & 0.86 & 8.7 \\
\hline & & & & 22 & 0.73 & 6.9 \\
\hline & & & & 23 & 0.70 & 6.92 \\
\hline & \multirow{4}{*}{$\begin{array}{l}\text { development of individual } \\
\text { capabilities }\end{array}$} & \multirow{4}{*}{0.50} & \multirow{4}{*}{13.81} & 24 & 0.70 & 12.14 \\
\hline & & & & 25 & 0.70 & 11.57 \\
\hline & & & & 26 & 0.75 & 11.23 \\
\hline & & & & 27 & 0.58 & 9.77 \\
\hline
\end{tabular}

Table 3

The standard factor load, meaningful statistics (t-value) scale of social capital

\begin{tabular}{|c|c|c|c|c|c|c|}
\hline Major variable & Minor variables & Factor load & t-value & questions & Factor load & t-value \\
\hline \multirow{17}{*}{ Organizational commitment } & \multirow{6}{*}{ continuous } & \multirow{6}{*}{$53 \%$} & \multirow{6}{*}{8.38} & 42 & 0.78 & 10.64 \\
\hline & & & & 43 & 0.85 & 11.57 \\
\hline & & & & 44 & 0.35 & 2.1 \\
\hline & & & & 45 & 0.36 & 4.41 \\
\hline & & & & 46 & 0.68 & 7.59 \\
\hline & & & & 47 & 0.38 & 3 \\
\hline & \multirow{6}{*}{ normative } & \multirow{6}{*}{$53 \%$} & \multirow{6}{*}{8.36} & 48 & 0.36 & 7.997 \\
\hline & & & & 49 & 0.36 & 4.18 \\
\hline & & & & 50 & 0.30 & 4.36 \\
\hline & & & & 51 & 0.36 & 5.55 \\
\hline & & & & 52 & 0.60 & 10.46 \\
\hline & & & & 53 & 0.53 & 10.22 \\
\hline & \multirow{5}{*}{ affective } & \multirow{5}{*}{$61 \%$} & \multirow{5}{*}{8.68} & 54 & 0.48 & 8.45 \\
\hline & & & & 55 & 0.85 & 13.58 \\
\hline & & & & 56 & 0.31 & 7.07 \\
\hline & & & & 57 & 0.48 & 8.58 \\
\hline & & & & 58 & 0.52 & 6.54 \\
\hline
\end{tabular}

Table 4

The standard factor load, meaningful statistics (t-value) scale of organizational commitment

\begin{tabular}{|c|c|c|c|c|c|c|}
\hline Major variable & Minor variables & Factor load & t-value & questions & Factor load & t-value \\
\hline \multirow{17}{*}{ Organizational commitment } & \multirow{6}{*}{ continuous } & \multirow{6}{*}{$53 \%$} & \multirow{6}{*}{8.38} & 42 & 0.78 & 10.64 \\
\hline & & & & 43 & 0.85 & 11.57 \\
\hline & & & & 44 & 0.35 & 2.1 \\
\hline & & & & 45 & 0.36 & 4.41 \\
\hline & & & & 46 & 0.68 & 7.59 \\
\hline & & & & 47 & 0.38 & 3 \\
\hline & \multirow{6}{*}{ normative } & \multirow{6}{*}{$53 \%$} & \multirow{6}{*}{8.36} & 48 & 0.36 & 7.997 \\
\hline & & & & 49 & 0.36 & 4.18 \\
\hline & & & & 50 & 0.30 & 4.36 \\
\hline & & & & 51 & 0.36 & 5.55 \\
\hline & & & & 52 & 0.60 & 10.46 \\
\hline & & & & 53 & 0.53 & 10.22 \\
\hline & \multirow{5}{*}{ affective } & \multirow{5}{*}{$61 \%$} & \multirow{5}{*}{8.68} & 54 & 0.48 & 8.45 \\
\hline & & & & 55 & 0.85 & 13.58 \\
\hline & & & & 56 & 0.31 & 7.07 \\
\hline & & & & 57 & 0.48 & 8.58 \\
\hline & & & & 58 & 0.52 & 6.54 \\
\hline
\end{tabular}




\section{The results}

\subsection{The final model of relationship between the variables and hypothetical proof}

The final structural equation model has been used to measure the relationship between three major structures of the research including work life quality of staff and organizational commitment and social capital. Since the structures of work life quality, organizational commitment and social capital have been made up of some other hidden variables, the average of obtained responses was calculated with the items of every variable and that variable has been used as an observed variable in the final model. The final model is presented in Fig. 2. This model has been designed by LISREL software output. The results from the meaningful evaluation of data model have also been presented in the diagram Fig. 3.

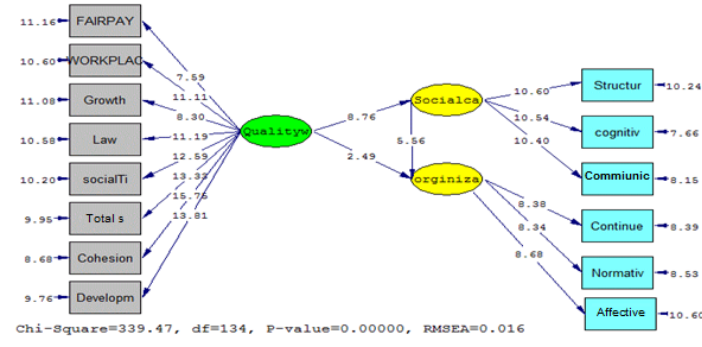

Fig. 2. The results of final model confirmation of relationship between work life quality, social capital and organizational commitment

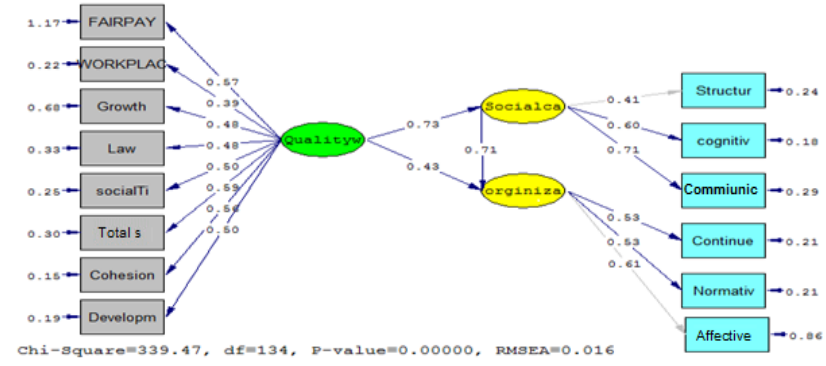

Fig. 3. The results of t-value statistics in the final model confirmation on the relationship between work life quality, social capital and organizational commitment

According to the calculations:

The standard factor load of the staff's work life quality and organizational commitment was obtained equal to $43 \%$ showing a strong and desirable relationship. The factor load of $t$ statistic was also obtained equal to 2.49 showing a meaningful co-relation. In addition, the standard the staff's work life quality and social capital was obtained equal to $73 \%$ indicating a highly strong and desirable relationship. The factor load of $t$ statistic was also obtained equal to 8.76 representing a meaningful co-relation. Finally, the standard factor load of the social capital quality and organizational commitment was obtained equal to $71 \%$ showing a highly strong and desirable relationship. The factor load of $t$ statistics was also obtained equal to 5.56 indicating a meaningful co-relation.

\subsection{The goodness of fit of the original research model}

To evaluate the original research model, some of the indices of the goodness of fit have been used. One of the general indices to consider the free parameters in the calculation of fit indices is the normative chi square test, which is obtained by the division of chi square bye the freedom degree of model. If it ranges from 1 to 5 , it is desirable (Kline, 2010) $\frac{\chi^{2}}{d f}=\frac{339.47}{134}=2.533$. In addition, since the root mean square error of approximation (RMSEA) is equal to 0.016 , the model has a good fitting. Other statistics are within the acceptable range shown Table 5.

\section{Table 5}

The summary of basic statistics

\begin{tabular}{|c|c|c|c|c|c|c|c|}
\hline Fit indices & IFI & NNFI & NFI & AGFI & GFI & RMSEA & SRMR \\
\hline Acceptable ranges & $0-1$ & $>0.9$ & $>0.9$ & $>0.9$ & $>0.9$ & $<0.05$ & $<0.05$ \\
\hline Calculated ranges & 0.94 & 0.95 & 0.95 & 0.93 & 0.93 & 0.016 & 0.016 \\
\hline
\end{tabular}

The equation model of final structure has been used to measure the relationship of each major structure of research (work life quality, social capital) with the hidden variables of organizational 
commitment (affective, continuous, and normative). Since the structure of staff's work life quality and social capital have themselves been composed of some other hidden variables, the resulting mean responses to items of each variable has been calculated and it has been used as observable variable in the final model. According to the calculation on the minor hypothesis of research:

The standard factor load of work life quality structure has been obtained with the variable of affective, continuous, and normative commitment as $89 \%, 63 \%, 74 \%$, respectively showing a highly strong and desirable relationship. The $t$ statistic factor load was obtained 5.20, 4.49, and 2.10, respectively indicating a meaningful and observable correlation. Therefore, the staff's work life quality and its items are effective on the affective, continuous, and normative commitment of the staff. Also the standard factor load of social capital structure was obtained with the variable of the affective, continuous, and normative commitment as $79 \%, 66 \%, 67 \%$, respectively indicating in highly strong and desirable relationship. The $t$ statistic factor load was obtained 4.42, 7.01, and 7.42, respectively representing a meaningful and observable co-relation. Therefore, the social capital is effective on the affective, continuous, and normative commitment of the staff.

\section{Conclusion and suggestions}

Job and employment are of the most important factors in life, which can bring about desirable conditions for the society if the individuals can be interested in and adopted to it. In other words, by improving the quality of life, work and following that organizational commitment, job satisfaction will be obtained. Social capital plays a much more important role than the physical and human capital in organizations and societies. In the absence of social capital, other capitals will lose their effectiveness, so it will be difficult to make a cultural and economic progress. Meanwhile, a highly organizational commitment will bring about the necessary productivity. Therefore, in the present research, the impact of work life quality and social capital on the organizational commitment of the tax affairs organization's staff of Lorestan province has been studied.

The results from the major and minor hypotheses of the research indicate that all the hypotheses, work life quality and social capital, are effective on the organizational commitment of the tax affairs organization's staff of Lorestan province. As shown in the internal and external researches such as Sayadee et al. (2009), Taleb-pour and Imami (2006), Mehdad et al. (2011), Hosseini et al. ( 2009), Lee et al. (2008 ), Johnsrud and Rosser (2002), Channg and Lee (2006), it can be noted that each of the above mentioned cases in the work life quality can improve the performance and the organizational commitment of the staff remarkably. Also, the results from the other hypothetical test of this research showed that social capital is effective on the organizational (affective, continuous, and normative) commitment of staff so that in the internal and external researches like Seyed Nagavi and Bahar (2009), Khorshid (2012), Macke et al. (2012), Kang (2012), this fact was the same and not only the tax affairs organization's staff of Lorestan province can increase the staff's social capital and improve the staff's life quality and finally improve their organizational commitment but also the personnel and managers of the other organization can perform this by employing the suitable approaches. This is accomplished by various factors such as increasing reliability among the staff and group members as well as the organizational units, teaching the staff, encouraging groups, establishing professional and specialized associations in the organization and providing suitable plants for the staff's work life quality.

\section{References}

Allen, N. J., \& Meyer, J. P. (1990). The measurement and antecedents of affective, continuance and normative commitment to the organization. Journal of occupational psychology, 63(1), 1-18.

Bolino, M. C., Turnley, W. H., \& Bloodgood, J. M. (2002). Citizenship behavior and the creation of social capital in organizations. Academy of management review, 27(4), 505-522. 
Channg, S.V., \& Lee, M. (2006). Relationship between personality traits, job characteristics, job satisfaction and organizational commitment: An empirical study. The Business Review, 6(1), 22130.

Chiu, C. M., Hsu, M. H., \& Wang, E. T. (2006). Understanding knowledge sharing in virtual communities: an integration of social capital and social cognitive theories. Decision support systems, 42(3), 1872-1888.

Dolan, S. L., García, S., Cabezas, C., \& Tzafrir, S. S. (2008). Predictors of "quality of work" and "poor health" among primary health-care personnel in Catalonia: Evidence based on crosssectional, retrospective and longitudinal design. International journal of health care quality assurance, 21(2), 203-218.

Ellinger, A. E., Musgrove, C. C. F., Ellinger, A. D., Bachrach, D. G., Elmadağ Baş, A. B., \& Wang, Y. L. (2013). Influences of organizational investments in social capital on service employee commitment and performance. Journal of Business Research, 66(8), 1124-1133.

Fiorito, J., Bozeman, D. P., Young, A., \& Meurs, J. A. (2007). Organizational commitment, human resource practices, and organizational characteristics. Journal of Managerial Issues, 19(2), 186207.

Fussell, H., Harrison- Rexrode, J. Kennan, W.R. \& Hazleton, V. (2006). The relationship between social capital, transaction costs, and organizational out comes: A case study. Corporate communications: An international journal, 11(2), 148-161.

Fakhrparvar, R., Yavari, Y., Amir Tash, A.M., Tond nevis, F. (2012). The relationship between quality work life and organizational commitment of faculty members from universities and educational groups of Physical training University in country. The Publication of Sports Management, 13, 154-156.

Griffin, R., \& Moorhead, G. (2011). Organizational behavior. Cengage Learning.

Harrison McKnight, D., Choudhury, V., \& Kacmar, C. (2002). The impact of initial consumer trust on intentions to transact with a web site: a trust building model. The Journal of Strategic Information Systems, 11(3), 297-323.

Hatami Hosseini, S. A., \& Muhahidi Jahromi, S. (2011). The relationship between quality of work life with organizational commitment and productivity level of medical sciences university's staff in Jahrom. Quarterly Journal of Scientific-Research, New Strategy in Educational Management, 2(3), 25-40.

Hersey, P., Blanchard, K. H., \& Johnson, D. E. (1996). Management of organizational behavior.

Hosseini, M.S., Naderian, M., Homaee, R., Homaee, R., \& Homaee, Z. (2009). The relationship between the quality of work life and organizational commitment of physical training department in Esfahan province. Journal of Sports Management, 2, 167-181.

Johnsrud, L. K., \& Rosser, V. J. (2002). Faculty members' morale and their intention to leave: A multilevel explanation. The Journal of Higher Education, 73(4), 518-542.

Kang, J.S. (2012). Relationship between the social capital, job satisfaction and organizational commitment in social welfare organization. Journal of the Korea Academia- Industrial Cooperation Society, 13(9), 3915-3923.

Kline, R. B. (2011). Principles and practice of structural equation modeling. Guilford press.

Krause, D. R., Handfield, R. B., \& Tyler, B. B. (2007). The relationships between supplier development, commitment, social capital accumulation and performance improvement. Journal of operations management, 25(2), 528-545.

Khorshid, S. (2012). A study on the effect of social capital on the staff's organizational commitment, the case study of the state bank in Kerman", the process of management development, 25(1), 115147.

Lau, R. S. (2000). Quality of work life and performance-An investigation of two key elements in the service profit chain model. International Journal of Service Industry Management, 11(5), 422-437.

Leana, C. R., \& Pil, F. K. (2006). Social capital and organizational performance: Evidence from urban public schools. Organization Science, 17(3), 353-366. 
Lee, S. H., Lee, T. W., \& Lum, C. F. (2008). The effects of employee services on organizational commitment and intentions to quit. Personnel Review, 37(2), 222-237.

Mathews, B. P., \& Shepherd, J. L. (2002). Dimensionality of Cook and Wall's (1980) British organizational commitment scale revisited. Journal of Occupational and Organizational Psychology, 75(3), 369-375.

Meyer, J. P., \& Allen, N. J. (1991). A three-component conceptualization of organizational commitment. Human resource management review, 1(1), 61-89.

Meyer, J. P., Allen, N. J., \& Smith, C. A. (1993). Commitment to organizations and occupations: Extension and test of a three-component conceptualization. Journal of applied psychology, 78(4), 538.

Mowday, R. T., Steers, R. M., \& Porter, L. W. (1979). The measurement of organizational commitment. Journal of vocational behavior, 14(2), 224-247.

Macke, J., Genari, D., \& Faccin, K. (2012). Social capital and commitment in the Brazilian wine industry. EJBO Electronic Journal of Business Ethics and Organization Studies, 17(1), 22-30.

Mehdad, A., \& Mahdavi-Rad, N., \& Golprou, M. (2011). The relationship between quality of work life dimensions with organizational commitment and its components. New Findings in Psychology, 5(20), 41-53.

Naghavi, M. A. S., \& Baharloo, A. S. (2014). The Role of Social Capital in Organizational Commitment Improvement at Iran National Oil Products Distribution Company (INOPDC), 8, 7651.

Nahapiet, J., \& Ghoshal, S. (1998). Social capital, intellectual capital, and the organizational advantage. Academy of management review, 23(2), 242-266.

Powell, D. M., \& Meyer, J. P. (2004). Side-bet theory and the three-component model of organizational commitment. Journal of vocational behavior, 65(1), 157-177.

Richards, B., O'Brien, T., \& Akroyd, D. (1994). Predicting the organizational commitment of marketing education and health occupations education teachers by work related rewards., 32(1), 114.

Sayadee touranlo, H., Jamali, R., \& Mansouri, H. (2009). The study of the relationship between quality work life and organizational commitment. Case study: the educational department staff of Yazd", magazine of educational sciences (educational sciences and Psychology) shahid Chamran university, Ahvaz, 5(16), 113-136.

Seyed Naqavi, M.A., \& Baharlou, A.A. (2009). The role of social capital in improving the organizational commitment in of National Iranian Oil products \& Distribution Company. The Quarterly Journal of Management Human Resources in the Oil Industry, 3(8), 51-76.

Taherian, M., Fereidoun, K., \& Kafashi, M. (2011). Impact of quality of work life on social capital of Raja company staff. Quarterly Journal of Social Research, 4(13), 59-82.

Taleb-pour, M., Imami, F. (2006). Study of the relationship between the organizational commitment, job dependence and its comparison between male physical education a teachers of the institutions in seven districts of Mashhad. Study in Sports Science, 12, 15-32.

Tsai, W., \& Ghoshal, S. (1998). Social capital and value creation: The role of intrafirm networks. Academy of management Journal, 41(4), 464-476.

Walton, R. E. (1973). Quality of working life-what is it. Sloan Management Review, 15(1), 11-21. 